\title{
Effect of oral 1,25 dihydroxycholecalciferol on calcium and phosphate malabsorption in primary biliary cirrhosis
}

\author{
K. FARRINGTON, O. EPSTEIN, Z. VARGHESE, S. P. NEWMAN, \\ J. F. MOORHEAD, AND S. SHERLOCK
}

From the Departments of Nephrology and Medical Physics and Medicine, Royal Free Hospital, London

SUMMARY Changes in calcium and phosphate absorption in response to treatment with small doses of oral $1,25(\mathrm{OH})_{2} \mathrm{D}_{3}$ were studied in 10 patients with primary biliary cirrhosis by means of a combined radio-isotope technique. There was a marked improvement in the fractional rates of absorption of calcium $(P<0.01)$ and phosphate $(0.05<P<0.1)$ after treatment. This implies that there is no end organ unresponsiveness to the action of active Vitamin $\mathrm{D}$ metabolites at the intestinal level in primary biliary cirrhosis.

Calcium and phosphate malabsorption is a recognised feature of primary biliary cirrhosis (PBC) (Whelton et al., 1971; Long et al., 1978b) and may contribute to the osteodystrophy seen in this condition. Vitamin D malabsorption is thought to be an important factor in this absorption defect (Whelton et al., 1971). Parenteral vitamin $D$ has been shown to improve calcium absorption in primary biliary cirrhosis, but the doses used were substantially greater than those required to correct the absorptive defects in nutritional osteomalacia (Whelton et al., 1971; Kehayoglou et al., 1968). On this basis, a state of relative vitamin $D$ resistance in primary biliary cirrhosis has been postulated. Possible causes of this resistance include impaired 25 hydroxylation of vitamin $\mathrm{D}$, abnormalities of the enterohepatic circulation of $25 \mathrm{OHD}$, increased urinary losses of vitamin D metabolites (Krawitt et al., 1977), impaired renal hydroxylation of $25 \mathrm{OHD}$, and end organ unresponsiveness to active vitamin D metabolites. The failure of large doses of parenteral $1,25(\mathrm{OH})_{2} \mathrm{D}_{3}$ to improve calcium absorption in primary biliary cirrhosis (Long et al., 1978a) may indicate a state of end organ unresponsiveness, though it is possible that the repeat absorption tests in this study were mistimed. The present study was undertaken to determine the effectiveness of small oral doses $\left(0.5 \mu \mathrm{g}\right.$ daily) of $1,25(\mathrm{OH})_{2} \mathrm{D}_{3}$ in correcting intestinal malabsorption of calcium and phosphate.

Received for publication 24 January 1979

\section{Methods}

Ten patients with histologically proven primary biliary cirrhosis were studied.

The clinical and biochemical details of the patients are shown in the Table. All the patients had been receiving regular monthly intramuscular injections of vitamins $A, D_{2}$, and $K$ since the time of diagnosis (two to six years) and oral cholestyramine in varying daily dosages. Three patients were receiving oral penicillamine ( $600 \mathrm{mg}$ daily).

Before each test the patients were maintained on a diet consisting of $800-1000 \mathrm{mg}$ calcium and 1000 $1200 \mathrm{mg}$ phosphate for at least five days. None of the patients had received parenteral vitamin $D$ in the preceding four weeks. All the tests were started at 9.0 a.m. after a 10 hour fast.

Combined radiocalcium and radiophosphate absorption tests were performed on each patient before starting treatment with oral $1,25(\mathrm{OH})_{2} \mathrm{D}_{3}$ ( $0.5 \mu \mathrm{g}$ daily). Plasma calcium and phosphate levels were estimated at fortnightly intervals throughout this treatment course. The absorption tests were repeated after four to 12 weeks (mean six weeks) of treatment.

The absorption tests consisted of the administration of oral doses of $5 \mu \mathrm{Ci}^{45} \mathrm{Ca}$ with $20 \mathrm{mg}$ calcium carrier and $5 \mu \mathrm{Ci}^{32} \mathrm{P}$ with $50 \mathrm{mg}$ phosphate carrier, dissolved in $250 \mathrm{ml}$ of dilute orange squash. Plasma samples were collected at $0,15,30,60,90$, and 120 minutes, and were decolourised by the addition of $30 \%$ hydrogen peroxide. Activity of 
Table Clinical and biochemical details of patients together with pre-treatment aCa and aPO

\begin{tabular}{|c|c|c|c|c|c|c|c|c|c|c|}
\hline Patient & $\operatorname{Age}(y r)$ & $\begin{array}{l}\text { Duration of } \\
\text { illness }(y r)\end{array}$ & $\begin{array}{l}\text { Histological } \\
\text { stage }\end{array}$ & $\begin{array}{l}\text { Serum } \\
\text { bilirubin } \\
(\mu \mathrm{mol} / l)\end{array}$ & $\begin{array}{l}\text { Alk. phos. } \\
(K A U / 100 \mathrm{ml}\end{array}$ & $\begin{array}{r}A S T \\
l(i u / l)\end{array}$ & $\begin{array}{l}\text { Plasma } \\
\text { Ca } \\
\text { (mmol/l) }\end{array}$ & $\begin{array}{l}\text { Plasma } \\
\text { POA } \\
\text { (mmol/l) }\end{array}$ & $\begin{array}{l}\text { Initial } \\
a C a\end{array}$ & $\begin{array}{l}\text { Initial } \\
a P O \text {. }\end{array}$ \\
\hline $\begin{array}{c}1 \\
2 \\
3 \\
4 \\
5 \\
6 \\
7 \\
8 \\
9 \\
10 \\
\text { Mean }\end{array}$ & $\begin{array}{l}53 \\
48 \\
43 \\
58 \\
53 \\
56 \\
58 \\
53 \\
49 \\
54 \\
52\end{array}$ & $\begin{array}{l}6 \\
4 \\
4 \\
6 \\
2 \\
2 \\
4 \\
4 \\
2 \\
2 \\
3 \cdot 6\end{array}$ & $\begin{array}{l}4 \\
3 \\
4 \\
4 \\
3 \\
3 \\
4 \\
3 \\
4 \\
3\end{array}$ & $\begin{array}{r}24 \\
15 \\
34 \\
28 \\
398 \\
30 \\
10 \\
60 \\
45 \\
153 \\
79\end{array}$ & $\begin{array}{r}64 \cdot 4 \\
28 \cdot 2 \\
70 \cdot 1 \\
60 \cdot 8 \\
206 \cdot 7 \\
45 \cdot 3 \\
25 \cdot 6 \\
29 \cdot 7 \\
95 \cdot 6 \\
108 \cdot 7 \\
75 \cdot 3\end{array}$ & $\begin{array}{r}43 \\
57 \\
37 \\
81 \\
150 \\
37 \\
18 \\
53 \\
63 \\
87 \\
62\end{array}$ & $\begin{array}{l}2 \cdot 48 \\
2 \cdot 63 \\
2.48 \\
2 \cdot 53 \\
2 \cdot 53 \\
2 \cdot 63 \\
2 \cdot 38 \\
2 \cdot 45 \\
2 \cdot 30 \\
2 \cdot 38 \\
2 \cdot 48\end{array}$ & $\begin{array}{l}1 \cdot 13 \\
1 \cdot 23 \\
1 \cdot 26 \\
1 \cdot 16 \\
1.26 \\
1.00 \\
0.97 \\
1 \cdot 16 \\
0.94 \\
0.74 \\
1.08\end{array}$ & $\begin{array}{l}0.25 \\
0.50 \\
0.05 \\
0.25 \\
0.05 \\
0.30 \\
0.30 \\
0.25 \\
0.20 \\
0.10 \\
0.22\end{array}$ & $\begin{array}{l}0.40 \\
0.40 \\
0.25 \\
0.30 \\
0.30 \\
0.20 \\
0.10 \\
0.20 \\
0.25 \\
0.15 \\
0.25\end{array}$ \\
\hline
\end{tabular}

${ }^{45} \mathrm{Ca}$ and ${ }^{32} \mathrm{P}$ in each sample was assayed by counting for 50 minutes in a Wallac liquid scintillation counter. About 5000 counts were obtained per sample in each of two counting channels. One channel was used to count ${ }^{32} \mathrm{P}$ activity only, while the other counted ${ }^{45} \mathrm{Ca}$ activity, but also contained a cross-over of about 2000 counts from ${ }^{32} \mathrm{P}$. Background in each channel was approximately 200 counts. Disintegrations per minute of each isotope were calculated by reference to quench curves, after correction for the cross-over of ${ }^{32} \mathrm{P}$ activity into the ${ }^{45} \mathrm{Ca}$ channel.

The percentage of the dose of each isotope present in the extracellular fluid pool was calculated for each sample time, and the fractional rates of absorption of calcium $(\alpha \mathrm{Ca})$ and phosphate $\left(\alpha \mathrm{PO}_{4}\right)$ calculated by the method of Marshall (1976). The curve of plasma levels against time was assumed to be a double exponential describing passage of the tracers through the plasma, and the method of least squares was used to find the best fit to the experimental results.

The normal ranges for the fractional rates of absorption of calcium and phosphate were established in 20 healthy volunteers. Combined doses of ${ }^{45} \mathrm{Ca}$ and ${ }^{32} \mathrm{P}$ were given to those control subjects over the age of 40 years. In younger subjects the ${ }^{47} \mathrm{Ca}$ and ${ }^{32} \mathrm{P}$ were administered singly but combined with carrier amounts of both calcium and phosphate. The normal ranges so established were comparable with those obtained by Marshall (1976) in a larger series of subjects, and are illustrated below in Fig. 2. Statistical methods used were the Wilcoxon matched pairs signed ranks test and Spearman's coefficient of rank correlation.

\section{Results}

The pre-treatment plasma calcium and phosphate concentrations were normal in all the patients except one, who was minimally hypophosphataemic. None of the patients became hypercalcaemic during treat- ment with $1,25(\mathrm{OH})_{2} \mathrm{D}_{3}$ and there was no statistical difference between pre- and post-treatment values of plasma calcium and phosphate.

Figure 1 shows the ${ }^{45} \mathrm{Ca}$ and ${ }^{32} \mathrm{P}$ activity time

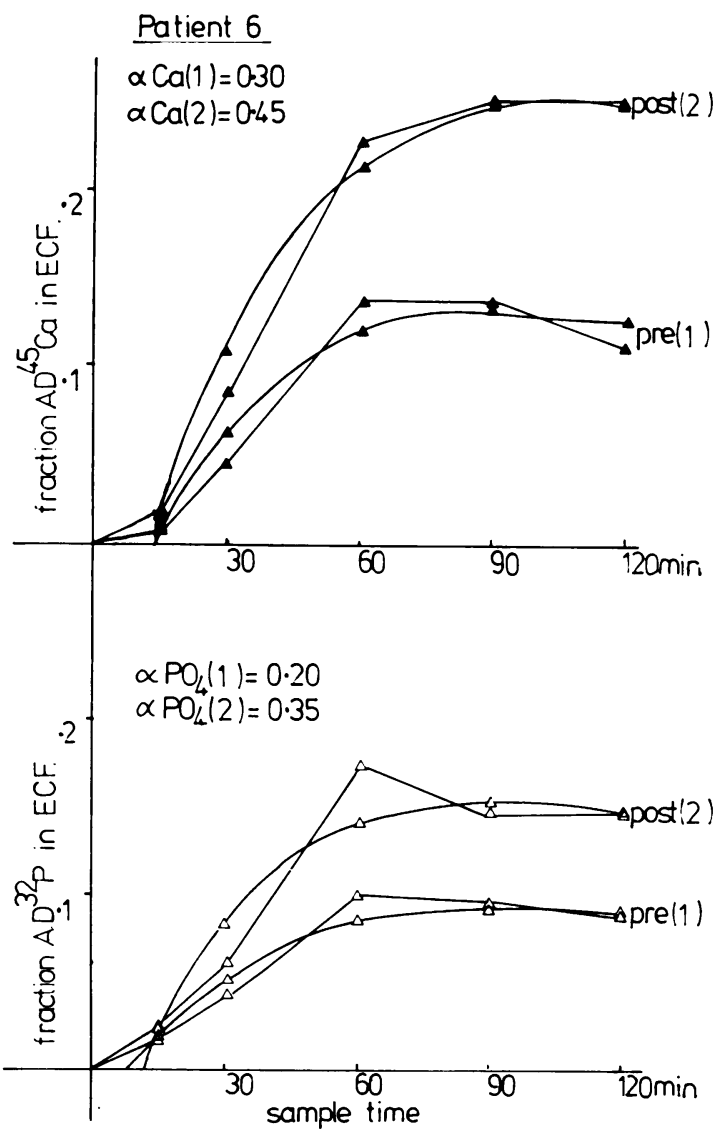

Fig. $1{ }^{45} \mathrm{Ca}$ and ${ }^{32} \mathrm{D}$ plasma activity together with fitted double exponential curves before and after treatment with 1,25 $(\mathrm{OH})_{2} D_{3}(A D$ : administered dose). 
curves in one patient (patient 6, Table), both before and after treatment with $1,25(\mathrm{OH})_{2} \mathrm{D}_{3}$ together with the fitted double exponential curves (Marshall, 1976). There is good discrimination between pre- and posttreatment curves for both isotopes, and a good approximation of the experimental data and fitted double exponential curves.

The responses to treatment of calcium $(\alpha \mathrm{Ca})$ and phosphate $\left(\alpha \mathrm{PO}_{4}\right)$ absorption are shown in Fig. 2. The mean pre-treatment mean of $\alpha \mathrm{Ca}$ value was low at $0 \cdot 22$. After treatment the mean $\alpha \mathrm{Ca}$ value improved to 0.48 , which represented a statistically significant improvement $(\mathrm{P}<0.01) . \alpha \mathrm{Ca}$ was improved by treatment in nine patients and there was no change in the remaining one. Seven patients had subnormal pre-treatment $\alpha \mathrm{Ca}$ values, while three post-treatment values remained subnormal.

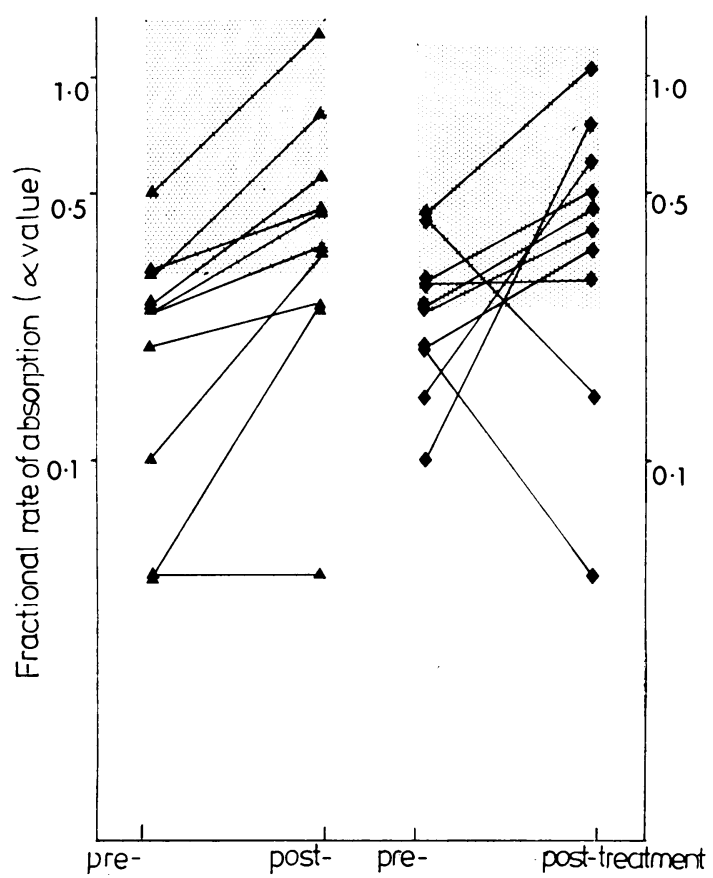

Fig. 2 Fractional rates of absorption per hour of calcium $(\mathrm{aCa})$ and phosphate $\left(\mathrm{aPO}_{4}\right)$ before and after treatment with $1,25(\mathrm{OH})_{2} \mathrm{D}_{3}$, plotted on log scale (Marshall 1976).

$\triangle a C a . \mathrm{aPO}_{4}$. Stippled area: normal range.

The pre-treatment mean of $\alpha \mathrm{PO}_{4}$ value was also low at $0 \cdot 25$. After treatment the mean value had improved to $0 \cdot 45$. This difference just failed to reach statistical significance $(0.05<\mathbf{P}<0.1) . \alpha \mathbf{P O}_{4}$ improved after treatment in seven patients and remained unchanged or fell in the remaining three.
Six patients had pre-treatment $\alpha \mathrm{PO}_{4}$ values at or below the lower limit of normal, while only two were subnormal after treatment. These two, however, included one patient with a normal pre-treatment value.

The increment in calcium absorption in response to treatment $(\Delta \alpha \mathrm{Ca})$ was positively correlated $(r=$ $0 \cdot 50)$ with that of phosphate absorption $\left(\Delta \alpha \mathrm{PO}_{4}\right)$, but this was not significant at the $5 \%$ level. There was, however, a significant correlation $(r=0.56$, $P<0.05)$ between the initial calcium absorption $(\alpha \mathrm{Ca})$, and the increment in calcium absorption $(\Delta \alpha \mathrm{Ca})$. There was no such correlation in the case of phosphate absorption.

\section{Discussion}

The fractional rates of absorption of calcium and phosphate as measured by this technique have been shown to agree with values obtained from balance studies (Marshall, 1976). Using this combined technique, we have confirmed that calcium and phosphate malabsorption often occurs in PBC patients.

An improvement in both calcium and phosphate absorption has been found in response to small oral doses of $1,25(\mathrm{OH})_{2} \mathrm{D}_{3}$. The improvement in phosphate absorption, however, was less pronounced than that of calcium, although in patients in whom there was an improvement in calcium absorption, there was usually also a comparable improvement in phosphate absorption. There were exceptions to this, however, and in two cases (patients 1 and 9, Table), phosphate absorption actually fell in spite of increased calcium absorption. The differential response to treatment in these two cases could not be accounted for in terms of the severity of their liver disease (Table). In addition, patient 5, who had the lowest initial calcium and phosphate absorption, showed no response to therapy with $1,25(\mathrm{OH})_{2} \mathrm{D}_{3}$, and, in general, the increment in calcium absorption in response to treatment was directly related to the pre-treatment calcium absorption. This suggests a greater requirement for $1,25(\mathrm{OH})_{2} \mathrm{D}_{3}$ in those patients with very poor calcium absorption. No such relation, however, existed in the case of phosphate absorption. The apparent differences in response between calcium and phosphate absorption may be artefactual in view of the small number of patients studied, but may also suggest fundamental differences in the regulation of absorption of these two substances (Norman, 1978).

Intestinal malabsorption of vitamin $\mathrm{D}$, due to reduced intraluminal bile salt concentrations is thought to be the major factor in calcium and phosphate malabsorption in patients with primary 
biliary cirrhosis (Whelton et al., 1971). The requirements of large parenteral doses of vitamin $\mathrm{D}$ to improve calcium malabsorption (Kehayoglou et al., 1968; Whelton et al., 1971), and the persistence of this malabsorption in spite of these measures (Ajdukiewicz et al., 1974), have been attributed to a state of relative vitamin $\mathrm{D}$ resistance. There appears to be no defect of hepatic 25 hydroxylation in these patients (Krawitt et al., 1977), and there is no real evidence to suggest impaired renal $1 \alpha$ hydroxylation. However, there are abnormal losses of vitamin D metabolites in the urine (Krawitt et al., 1977), and it has been suggested that the enterohepatic circulation of $25(\mathrm{OH})_{2} \mathrm{D}_{3}$ is defective (Compston and Thompson, 1977). These two factors, together with vitamin D malabsorption, could contribute to the state of vitamin D deficiency.

However, none of the above factors provides an adequate explanation for the failure of large parenteral doses of $1,25(\mathrm{OH})_{2} \mathrm{D}_{3}$ to improve calcium absorption in these patients (Long, 1978a). End organ resistance to the action of vitamin $\mathrm{D}$ metabolites is one such explanation, but the improvement in calcium and phosphate absorption in the present study in response to small doses of $1,25(\mathrm{OH})_{2} \mathrm{D}_{3}$ provides evidence that there is no such block to response at the intestinal level. These conflicting results are probably due to the inappropriate timing of the repeat absorption tests in the earlier study.

The clinical use of oral $1,25(\mathrm{OH})_{2} \mathrm{D}_{3}$ in the treatment of hepatic osteodystrophy will depend on whether or not oral administration proves effective in improving the histological abnormalities seen in these patients, and this remains to be established. However, 1,25 $(\mathrm{OH})_{2} \mathrm{D}_{3}$ is at present restricted in availability, unlike its analogue $1 \alpha \mathrm{OH} \mathrm{D}_{3}$, and we are currently evaluating the effectiveness of this latter compound in patients with primary biliary cirrhosis.

The authors would like to thank Dr N. T. Pollitt of Roche Products Ltd, for the supply of $1,25(\mathrm{OH})_{2} \mathrm{D}_{3}$. O.E. would like to thank Mr A. Chester Beatty for support.

\section{References}

Ajdukiewicz, A. B., Agnew, J. E., Byers, P. D., Wills, M. R., and Sherlock, S. (1974). The relief of bone pain in primary biliary cirrhosis with calcium infusions. Gut, 15, 788-793.

Compston, J. E., and Thompson, R. P. H. (1977). Intestinal absorption of 25-hydroxyvitamin $D$ and osteomalacia in primary biliary cirrhosis. Lancet, 1, 721-724.

Kehayoglou, A. K., Holdsworth, C. D., Agnew, J. E., Whelton, M. J., and Sherlock, S. (1968). Bone disease and calcium absorption in primary biliary cirrhosis. Lancet, 1 , 715-719.

Krawitt, E. L., Grundman, M. J., and Mawer, E. B. (1977). Absorption, hydroxylation, and excretion of vitamin $\mathrm{D}_{3}$ in primary biliary cirrhosis. Lancet, 2, 1246-1249.

Long, R. G., Varghese, Z., Meinhard, E. A., Skinner, R. K., Wills, M. R., and Sherlock, S. (1978a). Parenteral 1,25dihydroxycholecalciferol in hepatic osteomalacia. British Medical Journal, 1, 75-77.

Long, R. G., Varghese, Z., Skinner, R. K., Wills, M. R., and Sherlock, S. (1978b). Phosphate metabolism in chronic liver disease. Clinica Chimica Acta, 87, 353-358.

Marshall, D. H. (1976). Calcium and phosphate kinetics, in Calcium, Phosphate and Magnesium Metabolism. Clinical Physiology and Diagnostic Procedures, p. 257. Edited by B. E. C. Nordin. Churchill Livingstone: Edinburgh.

Norman, A. W. (1978). Calcium and phosphorus absorption, in Vitamin D, p. 111. Edited by D. E. M. Lawson. Academic Press: London, New York, San Francisco.

Whelton, M. J., Kehayoglou, A. K., Agnew, J. E., Turnberg, L. A., and Sherlock, S. (1971). Calcium absorption in parenchymatous and biliary liver disease. Gut, 12, 978-983. 